\title{
MODELLING OF FIRE IN AN OPEN CAR PARK
}

\author{
Timea Márton ${ }^{1}$, Anne Dederichs $^{2}$, Luisa Giuliani $^{2}$ \\ ${ }^{1}$ Optimise, London, UK \\ ${ }^{2}$ Civil Engineering Department, TechnicalUniversity of Denmark, Lyngby, DK
}

\begin{abstract}
Steel car parks exhibit high vulnerability to fire, as a consequence of the degradation of the steel mechanical properties at high temperatures and of the combustible type and amount. Real fire accidents in open car parks demonstrated a much faster and extended fire spread than predictions, assuming that a fire spread rate of 12 min and consider at most 3-4 vehicles on fire at the same time. Fire Dynamic Simulator (FDS) is applied in this current paper to study fire spread between cars. The outcomes of the investigations show that the fire spread is strongly influenced by the geometrical layout and that the distance between cars plays a determinant role on the fire spread rate and ignition of adjacent cars. In particular it was found that the fire spread can be faster than 12 minutes in the case of the cars parked 40 and $60 \mathrm{~cm}$ from each other.
\end{abstract}

Keywords: fire safety, open steel car park, computational fluid dynamic (CFD), fire spread.

\section{INTRODUCTION}

\subsection{Motivation}

Current assumptions for fire safety design of semi-open car parks are based on the premise that the fire severity is mitigated by the high ventilation of the premises, and that fire spread to adjacent vehiclesoccurs at every 12 minutes. These assumptions have led to the conclusion that the fire protection of some steel elements in open car parks could not be necessary(ISO/TC 92/SC4, 2005; Zhao \& Kruppa, 2004). However, the occurrence of some real car park fires involving a much larger and faster fire spread has called into question the reliability of current design practices.One of these fires occurred near Schiphol airport in October 2002, where around 30 cars have been seen on fire at the same time; more recently, a fire spread out in the open car park near the Aquatic Centre of the Sydney Olympic Park in October 2013: here a hundred cars were damaged by fire and 47 were completely burnt. Other faster spreading fires were reported in semi-open car parks(Daily Record, 2008; Fyens.dk, 2014), as well as in open air parking lots(The Guardian, 2013; Daily Mail Online, 2010; Daily Mail Online, 2014). The latter events clearly indicate that good ventilation is not sufficient in order to ensure a limited spread of the fire.

Another shortcoming of current design procedure has been outlined by research studies showing that the energy content of new generation cars is twice as high compared to old generation cars(Joyeux, 1997). This is primarily due to the higher amount of plastic and synthetic materials used in the process of car fabrication. A higher fire load would result in a more severe fire, which could cause more damage on the structure.

The choice of an appropriate heat release rate (HRR) model for carsand a realistic consideration of the fire spread among vehicles are therefore essential premises for a reliable fire safety design of car parks.The HRR has been object of several research studies (Mangs \& Keskirahkonen, 1994; Steinert, 2000). The CTCIMcentre in France has also carried out an experimental campaign on the new car models and determined a reference HRR curve for single vehicle firewith a peak value of 8.3 MW(Joyeux, 1997). They also suggest assumingthat fire spread will occur at every 12 minutes from one car to another. 
This paper is aimed at investigating further the parameters that play a role in the spread of fire from one vehicle to another in a well-ventilated car park. In particular, focus is given tothe sensitivity of the fire spread and time of ignition to design uncertainties such as the distance between cars and the geometrical layout of the cars with respect to the first ignition.

\section{APPROACH AND METHODOLOGY}

An open steel car park is taken as a case study and investigated under several different fire scenarios. The study employs a numerical model implemented in Fire Dynamic Simulator (FDS6). In particular, three different investigations are presented: i) a reference scenario considering only one car, used for model calibration and validation purposes; ii) a literature scenario following the assumptions of a fire spread rate limited to 12 minutes and involving 3 cars; iii) a free-spread scenario, where the fire spread was included in the model and different geometrical layout were considered.The results of the first two scenarios are validated against analytical solutions for simplified cases. Part of the validation is done by dividing the problem in simpler sub-problems that can be validated analytically.

The studied car park is a large construction with several spans of either 16 or 19 meters and a surface area ofone floor larger than $35000 \mathrm{~m}^{2}$. The structure is divided into several sub-structures independent from eachother and onlya part of the east sub-structure was considered in the model (highlighted with a red circle in Fig.1).
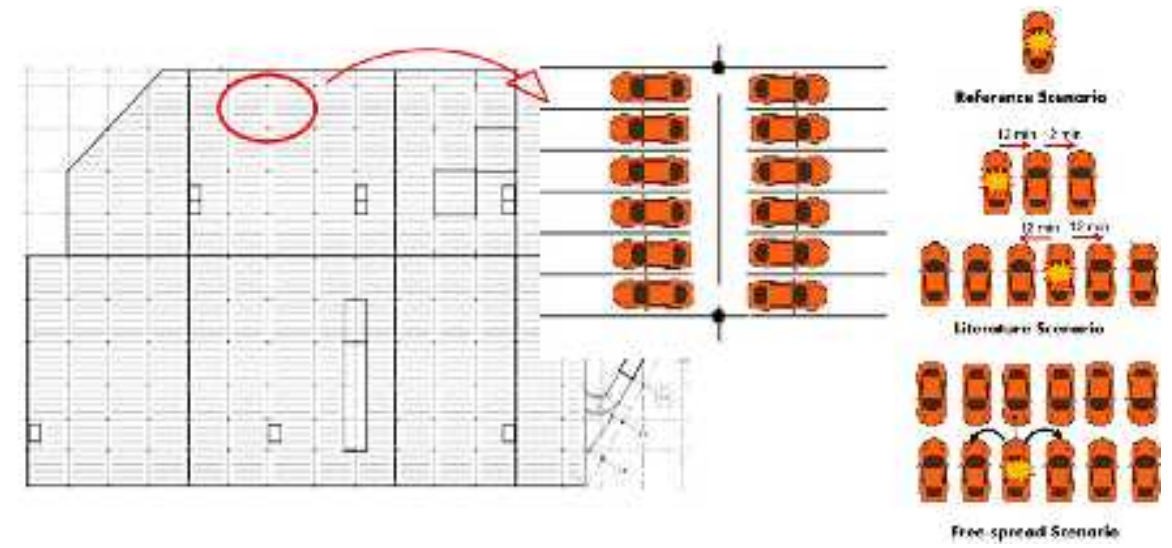

Fig.1Car park layout (left) and the three scenarios considered (right)

\subsection{Reference Scenario (i)}

This scenario has been developed with the scope of model calibration and validation and consists of a single burning vehicle with a simplified rectangular geometry and thermal properties that do not vary along the car. The size of the car is set to $1.8 \mathrm{~m} \times 4.8 \mathrm{~m}$ as indicated in Schleich (2010)and is assigned with the heat release curve indicated in the CTCIM report(Joyeux, 1997). The curve was chosen because it was determined in an experimental set-up approximately similar to an open car park layout.

The calibration of the model is done by a sensitivity study on the optimal mesh size andthe optimized model is used as reference for the rest of the scenarios. Preliminary validation of the model includes verification of the input HRR with the output HRR, verification of the mass burn rateand analytical validation of the smoke layer height and gas temperature against analytical formulas (Karlsson \& Quintiere, 1999). The preliminary benchmarks serve as support for validation of the final model.As the accuracy of the model is dependent on the input parameters, parameters includingthe appropriate HRR, radiation model and mesh size, flow mesh size, computational domain and fuel type have been analysed.Table 1 summarizes all these parameters and their set-up.

\subsection{Literature Scenario (ii)}

The scenario was developed with the scope of assessing the HRR and fire load considering the assumptions made by the CTICM (Joyeux, 1997; Joyeux, et al., 2002)and comparing them with the 
result of the free fire spread scenario. The scenario does not allow the fire to spread freely, but is limited instead to progress to the adjacent vehicles every 12 minutes. Two different cases where considered: a) a case with three cars and the fire initiating in one of the outer vehicles; and b) a case with six cars and the fire initiating in one of the middle cars. These assumptions were based on the suggestions given in the French guidelines for design of car parks (INERIS, 2001), according to which the scenario should take into consideration the disposition of the structural elements and that the fire load is dependent on the configuration of the parking layout and on the position of the fire initiation; hence a fire starting at the edge would involve at most 3-4 vehicles, while a fire starting in the middle could involve 6-7 vehicles.

\subsection{Free-spread Scenario (iii)}

The scenario was developed with the scope of investigating fire spread between vehicles considering different parking configurations.

The common width of a parking space was found to be varying between 2.3 and $2.5 \mathrm{~m}$, with either an inclination of $45^{\circ}$ or $60^{\circ}$ or with a perpendicular disposition(Schleich, 2010). Considering this, the average parking distance of $65 \mathrm{~cm}$ indicated in the European Guideline on design of closed car parks(Cajot, et al., 1999)and the minimum distance of $40 \mathrm{~cm}$ from the case of the Schiphol airport fire (Hertz-brand werkgroep, 2002), the following parking configurations have been determined:

- Configuration 1: parking distance $80 \mathrm{~cm}$, with a total of 12 cars

- Configuration 2: parking distance $60 \mathrm{~cm}$, with a total of 12 cars

- Configuration 3: parking distance $40 \mathrm{~cm}$, with a total of 14 cars

In all cases the cars were parked in two rows and the distance between the rows was considered to be the same as the distance adopted between two cars parked next to each other. The fire is assumed to start in one of the middle cars and the propagation to the adjacent cars is investigated under the following assumption:

- A uniform ignition temperature of the car surfaces, corresponding to that of natural rubber. This choice is motivated by the fact that rubber of the tires or in the windows is the first material that ignites in a car(Cajot, et al., 1999; BRE, 2010)

- The HRR curve indicated by the CTICM (Joyeux, 1997) for new car models, also used in the previous scenarios, assigned to each surface of the cars except the bottom one.

- A simplified shape of the cars, which were modelled as rectangular boxes. This simplification is justified by the fact that the fire spread was modelled exclusively from car to car, without considering the fire propagation between car parts.

After a study on the sensitivity of the fire spread model on the grid size, it has been determined that adopting the same cell size of $20 \mathrm{~cm}$ for all parking configurations lowers the accuracy of the results. As such, the mesh size in the area with the vehicles was refined in the model related to configuration 2 and 3 to 15 and $10 \mathrm{~cm}$, respectively.

Table 1 FDS Model set-up used in the fire simulations

\begin{tabular}{|c|c|c|}
\hline \multirow{2}{*}{ Domain } & size & $18 \mathrm{~m} \times 16.2 \mathrm{~m}$ room with $2.6 \mathrm{~m}$ outer extension for flow measurements across openings \\
\hline & \multicolumn{2}{|r|}{ flow mesh Rectilinear grid with size of $20 \mathrm{~cm}$, locally refined up to $5 \mathrm{~cm}$ in scenario iii). } \\
\hline \multirow[b]{2}{*}{$\begin{array}{l}\text { Boundary } \\
\text { conditions }\end{array}$} & sides & All boundaries are open to the outside \\
\hline & $\begin{array}{l}\text { top and } \\
\text { bottom }\end{array}$ & $\begin{array}{l}20 \mathrm{~cm} \text { thick concrete (conductivity } \mathrm{k}=0.8 \mathrm{~W} \mathrm{~m}^{-1} \mathrm{~K}^{-1} \text {, specific heat } \mathrm{c}=880 \mathrm{~J} \mathrm{~kg}^{-1} \mathrm{~K}^{-1} \text {, } \\
\text { density } \rho=2000 \mathrm{~kg} \mathrm{~m}^{-3} \text { ) }\end{array}$ \\
\hline \multirow{3}{*}{ Model } & fire & $\begin{array}{l}\text { Transient heat release curve from CTICM assigned to the car surfaces and ignition } \\
\text { temperature of rubber in scenario iii) for fire spread prediction. }\end{array}$ \\
\hline & radiation & Grey-gas radiation model with 100 discrete angles \\
\hline & turbulence & Low Mach, large-eddy simulation (LES) \\
\hline Analysis & setting & MPI processing, 4 meshes \\
\hline
\end{tabular}




\section{RESULTS}

The results of scenario ii) and iii) are reported in the following. For information on the validation of the model and the outcomes of scenario i), reference is made to (Marton, 2014).

Fig. 2 shows the resulting HRRs of the different configurations considered for the two scenarios. Both the maximum HRR and the total fire load (represented by the area subtended by the HRR curve) are smaller for scenario iii) than for scenario ii). However, towards the end of the fire the HRRs of all three configurations (corresponding to parking distance of 80,60 , and $40 \mathrm{~cm}$ ) of scenario iii) overcome the HRR of scenario ii), where only 3 cars are subsequently ignited.

By looking at the HRRs of scenario iii), it is possible to clearly distinguish two peaks of the HRR in all the three configurations considered. The first peak represents the time when the initially ignited car reaches its highest energy release rate. At this time, parts of the adjacent cars are already burning, as indicated by the fact that this peak is higher than the maximum HRR of $8.3 \mathrm{MW}$ assigned to the car where the fire originates. The second peak indicates the time when the first two adjacent cars reach the maximum heat release and correspond to a value of just $8 \mathrm{MW}$. This indicates that the full energy potential of the two cars is not reached, which indicates that only a part the car surfaces is burning.

The heat release for a parking distance of $40 \mathrm{~cm}$ is the highest among the three configuration of scenario iii) during the whole fire duration. As a consequence, the fire load associated to the smallest parking distance is also the highest. This indicates that, even if in all cases the fire involved a total of 7 cars, as better highlighted in the following, a bigger percentage of the car surfaces burns in case of a parking distance of $40 \mathrm{~cm}$.

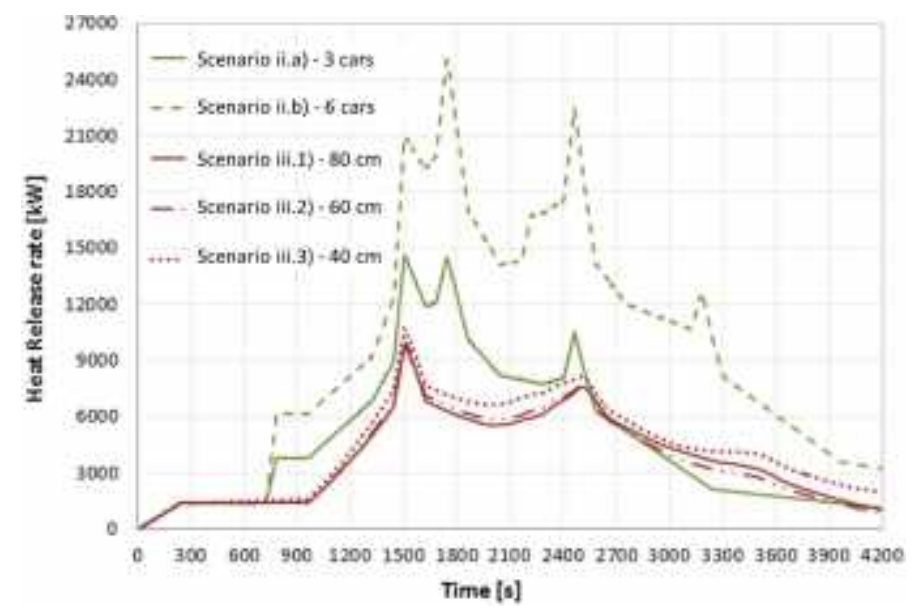

Fig.2 Comparison across the measured HRR in the different configurations of scenarios ii) and iii)

The outcomes of the investigations of the third scenario show that in all three configurations the fire propagated to a total of seven cars, before burning out after a time variable between 35 and 40 min. The order of ignition of the cars, which can be observed on the time-lines shown on the left part of Fig.3, is very similar for all three configurations:the $2^{\text {nd }}$ car igniting almost immediately after the first on, then the $3^{\text {rd }}$ car ignites, then $4^{\text {th }}$ and $5^{\text {th }}$ cars ignites almost simultaneously, and finally the $6^{\text {th }}$ and $7^{\text {th }}$ car ignite with a gap of few seconds from one another. . The pattern of the fire spread is also visible at the bottom of Fig.3, where the thermal map of the car surfaces at 40 min is reported and the isotherms corresponding to the ignition temperature are highlighted in black. Even though the fire spread pattern is the same in the three configurations, the ignition times of the cars, which can be read on the table reported on the right of Fig.3, vary with the parking distance. In particular, for a parking distance of 40 and $60 \mathrm{~cm}$ the time of ignition of the $1^{\text {nd }}$ car after the one where the fire originated is faster than the assumed 12 minutes and approximately equal to 6 and 9 min, respectively. In case of a parking distance of $80 \mathrm{~cm}$, the first fire spread occurs afterca. 16 min from the beginning of the fire. It is noted that the assumed time of 12 minutes was determined with the cars parked at $70 \mathrm{~cm}$ from each other, a time which falls in between the one measured for a distance of 60 and $80 \mathrm{~cm}$. 
By looking at the following rows of the table in the figure, it is noted that the sensitivity of the ignition time to the parking distance becomes smaller, as more cars are involved in the fire. In particular, the smallest difference is observed for ignition fo the $4^{\text {th }}$ and $5^{\text {th }}$ cars, occurring between 22 and 24 minutes in the three configurations. These times of ignition are relatively close to the time of peak heat release of the first car (occurring at $25 \mathrm{~min}$ ), which could explain the enhancement of the fire spread.

Another parameter that seems to play an important role in the fire spread from a car to the adjacent one is the size of the radiating surface of the first car. This can be seen in Fig. 4, where the variation of the ignition time of each car is plotted against the parking distance. The trend seems to be more than linear when the fire spreads from the long sides of the car and less than linear when it determined by radiation of the short side of the car.

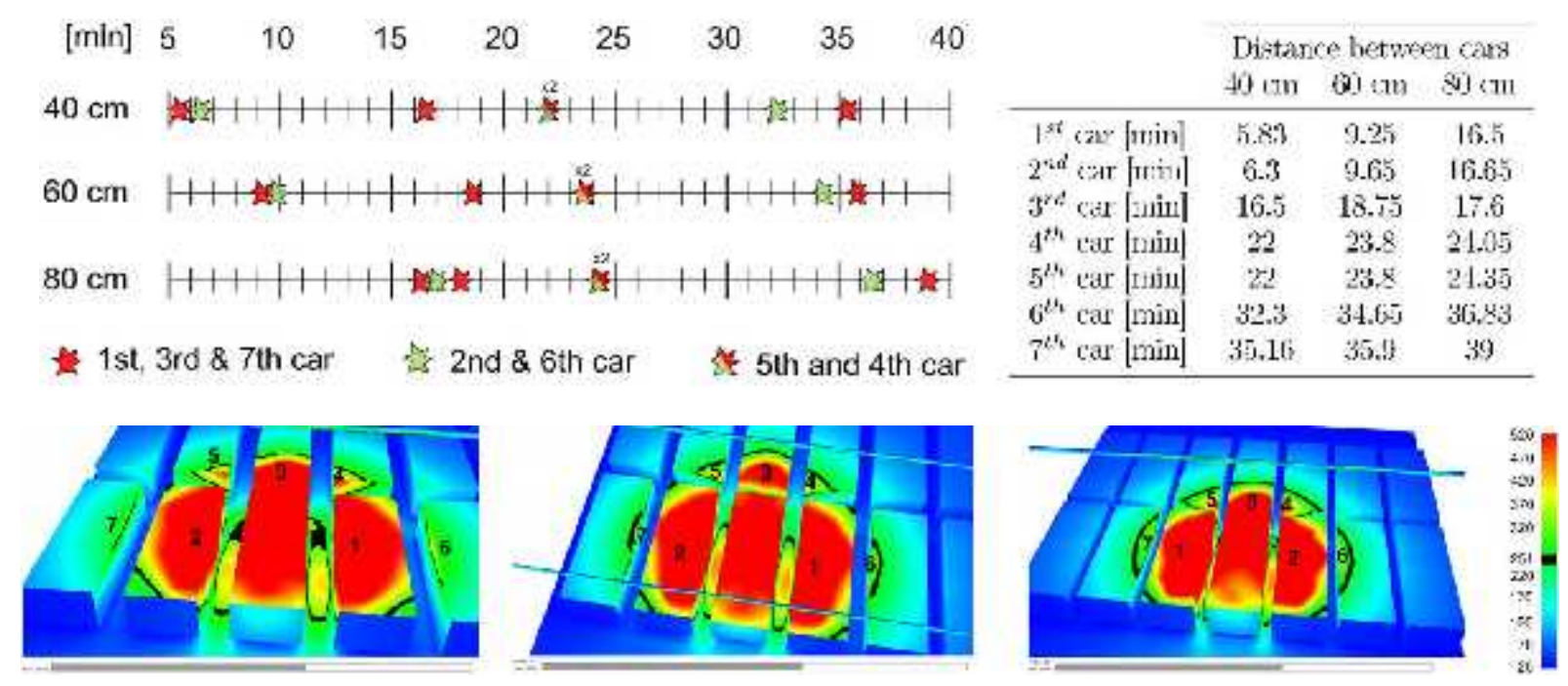

Fig.3Order of ignition of the cars in the three configurations $(40,60$, and $80 \mathrm{~cm}$ of parking distance) of scenario iii). Top: Time-lines of the subsequent ignitions (left) and table with the ignition times (right). Bottom:Surface temperature of the cars at $42 \mathrm{~min}$ from the beginning of the firein the three configurations (the ignition temperature is highlighted in black).

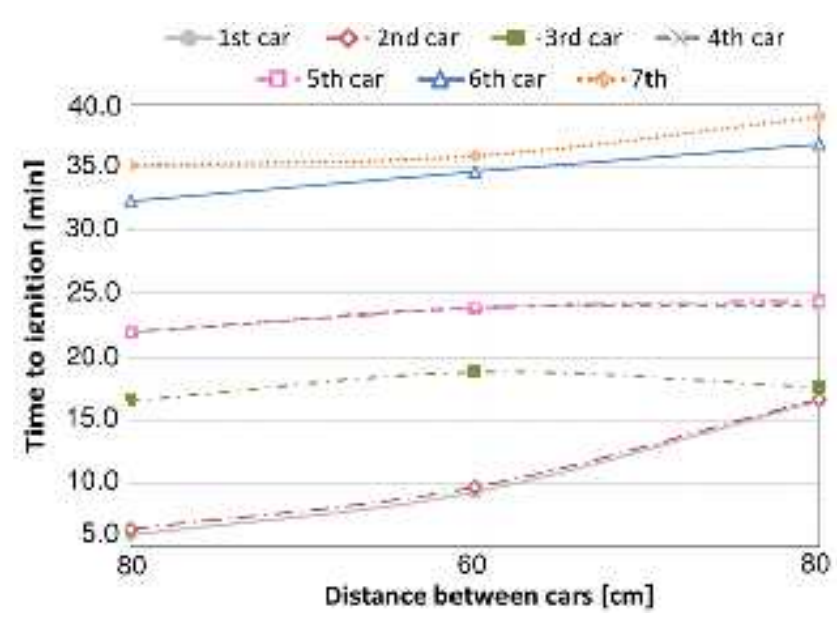

Fig. 4 Tendency of the ignition time with the parking distance

\section{CONCLUSION}

A CFD model of a car park has been implemented and used for investigating the parameters that play a role in the fire spread from one car to another. The outcomes of the investigations show that the fire spread is influenced by the geometrical layout. Specifically, the distance between the cars and the direction of the radiation play a determinant role in the ignition times of adjacent cars. In particular, the fire spread was faster than 12 minutes in the case of the cars parked 40 and $60 \mathrm{~cm}$ from each other. Even if in all configurations a total of 7 cars was involved in the fire (result that 
seems consistent with the indication given in the above mentioned French guideline (INERIS, 2001) in case of a fire starting in a middle car), the maximum HRR and the amount of combustible involved in the fire is slightly higher for a parking distance of $40 \mathrm{~cm}$.

The results were obtained by assuming a simplified model for the fire spread along the surfaces of each car, which were considered to have homogenous thermal properties corresponding to the car material that has the lowest ignition temperature (natural rubber). This assumption has no effect on the energy release rate of the cars, which is assigned in accordance to the experimental reference curve provided in (Joyeux, 1997). However, it may enhance the fire spread, in that it reduces the ignition timeof the surfaces corresponding to materials with a higher ignition temperature. On the other hand, it also induces a more uniform fire spread that may hinder the development of the entire energy potential of the carsand their total combustion. For this reason, the resulting HRR shows a slow evolution, with no significant peaks and no abrupt temperature increases, which are instead typical of car fires, where the burning of fuel or oil occurs at a high energy release. More refined models of the cars, which include the ignition temperatures of fuel, plastic, and upholstery, are under development, in order to better model the different ignition times of the various surfaces.

\section{REFERENCES}

BRE, 2010. Fire spread in car parks - BD2552. Technical report, London, UK: BRE - Department for Communities and Local Government.

Cajot, L., Pierre, M., Schleich, J. \& Brasseur, M., 1999. Development of Design Rules for Steel Structures Subjected to Natural Fires in Closed Car Parks - Report EUR 18867, Brussels: ECSC Steel Publication.

Daily Mail Online, 2010. Had a good break, Sir? Now about the vehicle you left in the long term car park 20 families' cars gutted at Stansted: http://www.dailymail.co.uk/news/article-1307422/Stansted-Airport20-families-cars-gutted-car-park-blaze.html [Online, Accessed May 2015].

Daily Mail Online, 2014. Edinburgh Airport fire, 2014. www.dailymail.co.uk/news/article-2613019/Thatsnot-wantcome-home-More-20-vehicles-destroyed-huge-blaze-airport-car-park.html [Online, Accessed May 2015].

Daily Record, 2008. Kilmarnock's Foregate fire. www.dailyrecord.co.uk/news/local-news/car-catches-firekilmarnocks-foregate-2444288[ [Online, Accessed May 2015].

Fyens.dk, 2014. Car park fire in Odense (Beboere evakueret: 10 biler brød i brand i Hjallese - in Danish). http://www.fyens.dk/Odense/Beboereevakueret...iHjallese/artikel/2485817 [Online, Accessed May 2015].

Hertz-brand werkgroep, 2002. Fire investigation report of the car park fire in Schiphol (Onderzoeksrapportage parkeergarage brand te Schiphol, in Dutch), The Netherland: Brandweer Haarlemmermeer - Brandweer Schiphol.

INERIS, 2001. Parcs de stationnement en superstructure largement ventiles (in French), France: Institut National de l'Environnement Industriel et des Risques.

ISO/TC 92/SC4, 2005. Fire safety engineering Performance of structures in Fire Part 3: Example of an open car park, s.l.: ISO Standards.

Joyeux, D., 1997. Natural Fires in closed Car Parks - Car Fire Tests. Technical Report , s.1.: CTICM Department Incendie et Essais.

Joyeux, D. et al., 2002. Demonstration of real fire tests in car parks and high buildings - Final report, SaintRemy-Les-Chevreuse Cedex, France: CTICM -Département Incendie et Essais.

Karlsson, B. \& Quintiere, J., 1999. Enclosure Fire Dynamics. Florida, US: CRC Press LLC.

Mangs, J. \& Keskirahkonen, O., 1994. Characterization of the fire behavior of a burning passenger car - Part I: Car fire experiments. Fire Safety Journal, 23(1), pp. 17-35.

Marton, T., 2014. Fire modelling in open car parks using FSD, Lyngby: Technical University of Denmark.

Schleich, J., 2010. Modern Fire Engineering, Fire Design of Car Parks, s.1.: Arcelor Profil, Luxembourg.

Steinert, C., 2000. Experimental Investigation of Burning and Fire Jumping Behavior of Automobiles (in German). Vereinigung zur Förderung des Deutschen Brandschutzes (VFDB), Volume 49, pp. 163-172.

The Guardian, 2013. Sydney Olympic Park fire destroys 47 cars, damages 33. [Online, Accessed May 2015] http://www.theguardian.com/world/2013/oct/14/sydney-olympic-park-fire-destroys-47-cars-damages-33.

Zhao, B. \& Kruppa, J., 2004. Structural behaviour of an open car park under real fire scenarios. Fire and Materials, 28(2-4), pp. 269-280. 